\title{
A multicenter point-prevalence study: antimicrobial prescription frequencies in hospitalized patients in turkey
}

\author{
Gaye Usluer*1, Ilhan Ozgunes ${ }^{1}$, Hakan Leblebicioglu ${ }^{2}$ and the Turkish \\ Antibiotic Utilization Study Group
}

\author{
Address: ${ }^{1}$ Osmangazi University, Faculty of Medicine, Department of Infectious Diseases, Eskisehir-Turkey and ${ }^{2}$ Ondokuz Mayis University, \\ Faculty of Medicine, Department of Infectious Diseases, Samsun-Turkey \\ Email: Gaye Usluer* - gusluer@ogu.edu.tr; Ilhan Ozgunes - iozgunes@ogu.edu.tr; Hakan Leblebicioglu - hakanomu@omu.edu.tr; the Turkish \\ Antibiotic Utilization Study Group - hakanomu@omu.edu.tr \\ * Corresponding author
}

Published: 03 October 2005

Annals of Clinical Microbiology and Antimicrobials 2005, 4:16 doi:10.1 186/1476-07II-4-16

This article is available from: http://www.ann-clinmicrob.com/content/4/1/16

(C) 2005 Usluer et al; licensee BioMed Central Ltd.

This is an Open Access article distributed under the terms of the Creative Commons Attribution License (http://creativecommons.org/licenses/by/2.0), which permits unrestricted use, distribution, and reproduction in any medium, provided the original work is properly cited.
Received: 20 June 2005

Accepted: 03 October 2005

\begin{abstract}
Background: Accurate information about prescribing patterns in hospitals is valuable in improving the quality of antimicrobial prescriptions.

Methods: Data on the use of antimicrobial agents in eighteen tertiary care hospitals were collected on March 20th 2002.

Results: One or more antimicrobials were ordered in 2900 (30.6\%) of 947I hospitalized patients. The reasons of hospitalization of the patients receiving antimicrobials were medical treatment $(42.5$ $\%)$, elective surgery (39.6\%), treatment of infectious disease (17.1\%) and emergent surgical procedures $(10.4 \%)$. The highest consumption frequencies were found in surgical $(81.6 \%)$ and medical $(55.2 \%)$ intensive care units. The $48.8 \%$ of antimicrobials were given for treatment and $44.2 \%$ for prophylactic use. The most common reasons for treatment were found as lower respiratory tract, urinary tract, surgical wound infections and febrile neutropenia. Antimicrobials were ordered empirically in $78.4 \%$ of patients. The proven infection ratio was found as $30.7 \%$. The $56.4 \%$ and $13.4 \%$ of orders were evaluated as clinically and microbiologically appropriate respectively.
\end{abstract}

Conclusion: These results suggest that antimicrobial prescription and empirical treatment ratios were high and inappropriate at inpatient groups.

\section{Introduction}

Since antimicrobial chemotherapy was introduced in medical practice, there have been calls for its rational use. Appropriate antimicrobial treatment greatly improves the prognosis of infectious diseases. There has been a very significant reduction in morbidity and mortality associated with the use of antimicrobials since they were first introduced [1]. However, the overuse of antimicrobials may increase the risks of drug resistant pathogens, side effects and costs of medical care. The right agent at the right dose and dosing interval and right duration can achieve both a favorable clinical outcome and prevent the selection of 
Table I: Hospitalized, antimicrobial receiving patients and hospitalization reasons of antimicrobial prescribed patients in 18 centers.

\begin{tabular}{lrr}
\hline & $\mathrm{n}$ & $\%$ \\
\hline Hospitalized patients & 9471 & 100 \\
\hline Antimicrobial receiving patients & 2900 & 30.6 \\
\hline Hospitalization reason & & \\
\hline Medical treatment & 1231 & 42.5 \\
Elective surgery & 1147 & 39.6 \\
Treatment of an infectious diseases & 497 & 17.1 \\
Emergent surgery & 303 & 10.4 \\
Other reasons & 73 & 2.5 \\
\hline
\end{tabular}

resistance. It was reported that $20-50 \%$ of antimicrobial use in humans was questionable or inappropriate $[1,2]$. Accurate information about prescribing patterns in hospitals is valuable in improving the quality of antimicrobial prescriptions.

Only very limited data on the usage of antimicrobials in Turkey $[1,3]$. The over use of antimicrobials increases the risk of drug resistant pathogens, side affects and cost of medical care [4]. This multicenter study was planned as a point-prevalence study to evaluate antimicrobial prescription frequency and patterns in tertiary care hospitals in Turkey.

\section{Materials and methods}

This prospective study was conducted in eighteen tertiary care hospitals from 14 different cities located in seven geographical regions of Turkey. These hospitals were representing approximately $30 \%$ of all tertiary care hospitals in Turkey. Data on the use of antimicrobial agents in these hospitals were collected by infectious diseases consultants on March $20^{\text {th }} 2002$. The same methodology was used for all hospitals. All patients who have received antimicrobials for any reason were included to this study. The data was included to the study within the first week of the study day, if there was a delay in the recording of data for any reason such as unavailable culture results which the specimen for this culture was collected before or on March $20^{\text {th }} 2002$.

In the study, total bed capacities of hospitals, number of hospitalized patients, the type and number of antimicrobial prescriptions, the main diagnosis which the prescription was made, clinical and microbiological evidences for treatment were recorded. The presence of an infectious disease was diagnosed according to signs and symptoms, non-microbiological and microbiological laboratory findings and defined as proven infection.

For patients receiving antimicrobials, demographic data, reason for admission and hospitalization, results of microbiological samples, name and dosage of antimicrobials and indication for antimicrobials were recorded on special forms. The antimicrobial regimes were evaluated according to choice, combination, duration and dose of the antimicrobials.

Hospital and patients details were recorded in two different forms. The first one was for the hospital details such as the name of the hospital, total bed capacity, departments and their bed capacities, total number of hospitalized patients of the hospital and of each department on the study day. The second form was used for recording data of patients which were receiving an antimicrobial agent on the study day. All of the records were collected and evaluated by the principal investigators in the study center. All of the data was transferred to the computer using a file designed by Dr. Ozgunes with Microsoft Access.

The antimicrobial prescription ratio, hospitalization reason of antimicrobial receiving patients and combination therapies were evaluated. Antimicrobial prescriptions were globally considered inappropriate if any of the assessed criteria appeared unacceptable, according to indication or antimicrobial choice, dosage errors, and duration of treatment. Appropriateness of antimicrobial prescriptions was evaluated according to the clinical and laboratory findings on the beginning of the therapy.

Statistical analyses were made by chi square test.

\section{Results}

Eighteen tertiary care hospitals from 14 different cities of Turkey included to the study. 9471 hospitalized patients were evaluated. One or more antimicrobials were ordered in $2900(30.6 \%)$ of 9471 patients. In the antimicrobial receiving group $1232(42.5 \%)$ patients were hospitalized for medical treatment, 1147 (39.6\%) for elective surgery, $497(17.1 \%)$ for infectious diseases, $303(10.4 \%)$ for emergent surgery and $73(2.5 \%)$ for other reasons. There were more than one hospitalization reasons for some patients (Table 1).

The highest antimicrobial consumption ratios were found in intensive care units (ICU) (Surgical ICU 81\%, medical ICU $52.5 \%$ ). Antimicrobial consumption frequencies according to departments (surgical/medical) were shown in table 2.

The indications of antimicrobial therapy were also evaluated. The $48.8 \%$ of antimicrobials were given for treat- 
Table 2: The distribution of antimicrobial prescribed patients to hospitalized patients.

\begin{tabular}{|c|c|c|c|}
\hline & Antimicrobial prescribed & Total hospitalized & $\begin{array}{c}\text { Percentage of antimicrobial } \\
\text { prescribed }\end{array}$ \\
\hline Surgical Clinics & 1414 & 4172 & $33.9 \% *$ \\
\hline Medical Clinics & 1138 & 4529 & $25.1 \% *$ \\
\hline Surgical ICU & 107 & 132 & $81 \% *$ \\
\hline Medical ICU & 83 & 158 & $52.5 \% *$ \\
\hline Total & $2900 * *$ & $947 \mid$ & $30.6 \% *$ \\
\hline
\end{tabular}

ICU: Intensive care unit.

*The ratios were found statistically different $\left(x^{2}=119 S D=2, P<0.001\right)$.

**The wards of 158 patients were not reported.

Table 3: The appropriate prescription in patients receiving prophylactic antimicrobials and the proven infection, clinically and microbiologically appropriate treatment ratios in patients that were treated for an infection.

\begin{tabular}{|c|c|c|c|}
\hline & & $\mathbf{n}$ & $\%$ \\
\hline \multirow[t]{4}{*}{ Prophylactic antimicrobial use } & Appropriate & 671 & $52.46 *$ \\
\hline & Inappropriate & 423 & $33.07^{*}$ \\
\hline & Not reported & 185 & 14.46 \\
\hline & TOTAL & 1279 & \\
\hline \multirow[t]{5}{*}{ Clinically } & Proven infection & 807 & 57.15 \\
\hline & Appropriate & 869 & $61.54 * *$ \\
\hline & Inappropriate & 364 & $25.77^{* *}$ \\
\hline & Not reported & 179 & 12.67 \\
\hline & TOTAL & 1412 & 100 \\
\hline \multirow[t]{5}{*}{ Microbiologically } & Appropriate & 274 & $84.04 * * *$ \\
\hline & Inappropriate & 52 & $15.95 * * *$ \\
\hline & Not reported & 88 & 6.23 \\
\hline & TOTAL & $4 \mid 4 * * * *$ & 100 \\
\hline & No microbiological data & 986 & 69.83 \\
\hline
\end{tabular}

\footnotetext{
$*_{\mathrm{t}}=9.91, \mathrm{SD}=1092, \mathrm{p}<0.00$

$* *_{t}=19.16, S D=|23|, p<0.001$

$* * * * 15.79, \mathrm{SD}=324, \mathrm{p}<0.001$

******The microbiological data was not available for all patients.
}

ment of an infectious disease and $44.2 \%$ for surgical antimicrobial prophylaxis. It wasn't found any reason for antimicrobial prescriptions in 204 (7\%) patients' records. More than one reason was reported for some patients.

Antimicrobial prescriptions were made empirically in $2275(78.4 \%)$ of patients and according to microbiological data in $334(11.5 \%)$.

The proven infection ratio was found as $30.7 \%$ in 2900 patients and $57.15 \%$ (807 of 1412) in treatment group. The antimicrobial prescriptions were evaluated by the investigator if or not they were appropriate to clinical and microbiological data. The $56.4 \%$ and $13.4 \%$ of orders were evaluated as clinically and microbiologically appro- priate respectively in 2900 patients. In patients receiving prophylactic antimicrobials $671(52.46 \%)$ of 1279 prescription were evaluated as appropriate (Table 3 ). The $61.54 \%$ (869 of 1412 ) prescriptions were evaluated as clinically appropriate in patients receiving antimicrobials for treatment (Table 3). There was not any microbiological data in $986(69.83 \%)$ patients in this group. The microbiologically appropriate prescription ratio was found $84.04 \%$ in 326 patients with microbiological data. The appropriate and inappropriate prescription in treatment group was given in table 3 .

The combination therapy ratio was found as 33\%. 50 patients including tuberculosis cases were receiving more than three antimicrobials. 25 patients were receiving com- 
Table 4: The most common prescribed antibiotic groups in hospitalized patients and the most common used antibiotics in combinations.

\begin{tabular}{lll}
\hline Antibiotic group & Prescription \% & Combination \% \\
\hline Penicillines & 23.6 & 18.8 \\
I.Generation Cephalosporins & 14.6 & $\mathbf{7 . 1}$ \\
2.Generation Cephalosporins & 5.3 & 0.0 \\
3.Generation Cephalosporins & 23.7 & 21.1 \\
4.Generation Cephalosporin & 4.2 & 4.5 \\
Aminoglycosides (Excluding streptomycin) & 17.2 & 30.8 \\
Carbapenems & 6.5 & 10.9 \\
Glycopolypeptides & 4.8 & 13.1 \\
Ornidazole-Metronidazole-Clindamycin & 9.9 & 18.2 \\
Quinolones & 14.4 & 11.9 \\
Macrolides & 3.0 & 4.7 \\
Tetracyclines & 0.7 & 1.2 \\
Antifungal agents & 3.4 & 4.3 \\
\hline
\end{tabular}

bination therapy because of tuberculosis. $453(15.6 \%)$ of patients were receiving three antimicrobials and 428 of them $(14.7 \%)$ were non-tuberculosis patients.

The most common prescribed antibiotics were cefazolin, ampicillin-sulbactam, ceftriaxone, ciprofloxacin, amikacin, gentamicin, ornidazole, cefuroxime, meropenem and vancomycin. The prescription ratios of antibiotic groups were given in table 4 .

The most common used antibiotics in combinations were aminoglycosides $(30.8 \%), 3^{\text {rd }}$ generation cephalosporins $(21.1 \%)$, penicillins $(18,8 \%)$, ornidazole-metronidazolclindamycin $(18.2 \%)$, glicopolypeptides $(13.1 \%)$, quinolones $(11.9 \%)$ and carbapenems (10.9\%) (Table 4). The $88.5 \%$ of combined aminoglycosides were used in combination with beta-lactams and glycopolypeptides. There were 15 combinations of sulbactam-ampicillin with clindamycin, ornidazole or metronidazol. We determined that $67.44 \%$ of the patients were in official health insurance systems and $19.7 \%$ of them were in official social assistance system.

\section{Discussion}

Although the principles of rational antimicrobial usage have been well defined for many years, inappropriate use of antimicrobials remains wide spread. The cost, adverse effects and development of resistance are main problems in wide spread usage of antimicrobials. The emergence and spread of drug resistant pathogens have already become a very serious problem internationally. It was reported that $14 \%$ and $43 \%$ of all courses of antimicrobial chemotherapy were deemed unnecessary because there was no evidence of infection $[2,5,6]$.
In this study, antimicrobial prescription frequency was found as $30.6 \%$ in hospitalized patients. The antibiotic prescription frequency was reported as $77.8 \%$ from a university hospital in China, and as $65 \%$ from a pediatric teaching in Costa Rica [6,7]. Empirical antimicrobial prescription and combination antimicrobial treatment ratios were high $(78.4 \%, 33 \%)$ in the study group also. The problem is more serious in ICU and surgical departments than medical departments. The antimicrobial prescription ratios were higher in ICU's ( $81 \%$ of surgical ICU, $52.5 \%$ of medical ICU) than other departments of hospitals ( $\mathrm{P}<$ 0.001 ). It was reported that the $58.0 \%$ of surgical ICU patients in a university hospital from Germany were receiving antibiotics [8]. The antibiotic prescription frequency was reported as 6.55 and $14.4 \%$ from two different pediatric ICUs from Israel [9]. The proven infection ratio was found as $30.7 \%$ in the appropriate antimicrobial treatment given group and $57.9 \%$ in the inappropriate antimicrobial treatment group. The results of the study showed that inappropriate antimicrobial prescription was an obvious problem in the study hospitals of Turkey. More than $40 \%$ of antimicrobial prescriptions were made without a proven infection. Inappropriate antimicrobial usage is a worldwide problem. $40 \%$ of antibiotic prescriptions were reported that had no record of justification and $55 \%$ of prescriptions had no indication of planned duration of therapy [7].

The $44 \%$ of antimicrobial prescriptions were made for surgical prophylaxis and $52.4 \%$ of them were appropriate. This group was seemed to be increasing the inappropriate prescription ratios because of the long duration usage and wrong selection of antimicrobials. Hu et al reported that $30 \%$ of hospitalized patients were receiving perioperative antibiotics and $20 \%$ of them received antibiotics before or 
during operation and $80 \%$ of them after operation. The duration of perioperative antibiotic prophylaxis was less than or equal to seven days in $42.7 \%$ of patients, $8-13$ days in $31 \%$, and 14 days or more in $26.3 \%$ [6]. In another study reported by Bailly et al, the rate of compliant prescription for surgical prophylaxis was $41.7 \%$ [10].

Also the combination therapy ratios were found as high as $33 \%$ of total antimicrobial prescribed patients. It can be thought that there is a relation between high empirical antimicrobial treatment and high combination therapy ratios. The limited microbiological evidence for the diagnosis of infection can be thought as another reason for high ratios of empirical and combination therapies because of the microbiologically appropriate and inappropriate usage ratios were found as $84.04 \%$ and $15.95 \%$ respectively in the treatment group. These results suggest that a multidisciplinary antimicrobial management system is required in hospitals because of the high proportion of empirically treatment and inappropriate use of antimicrobials. The system must have legal support and the antimicrobial control teams must be include the departments of infectious diseases, microbiology, pharmacy, and infection control [1]. Also there is need good microbiological support for clinicians to increase the appropriate prescription rate. Local and practical antimicrobial treatment guidelines for clinicians and continuous education programs may decrease the inappropriate, empirical and combination therapy ratios.

The cost of antimicrobials is another serious problem for insurance systems in Turkey. The anti-infective drugs are the most used drugs ( $22 \%$ of all drugs) in our country. The annually antimicrobial and total drug cost for per person was calculated as $\$ 8,4$ and $\$ 38$ in Turkey [11].

In conclusion, this point-prevalence study revealed that more than $50 \%$ of patients received inappropriate antimicrobial prescriptions. We thought that only restricted prescription procedures are not enough for the reduction of inappropriate antimicrobial rates. A general antimicrobial treatment program must include education, guidelines, restricted usage, control of the hospital pharmacies and automatic discontinuation by the hospital pharmacies.

\section{Acknowledgements}

Turkish Antibiotic Utilization Study Group: Halis Akalın, Celal Ayaz, Rahmet Caylan, Yesim Cetinkaya Sardan, Nese Demirturk, Ilknur Erdem, Funda Ergin, Serpil Erol, Saban Esen, Sibel Gündes, Iftihar Koksal, Oral Oncul, Kazim Ozdamar, Recep Ozturk, Fatma Sirmatel, Irfan Sencan, Yesim Tasova, Gunay Tuncer, Sercan Ulusoy, Serhat Unal, Haluk Vahaboglu, Tansu Yamazhan (In alphabetical order)

\section{References}

I. Guven GS, Uzun O: Principles of good use of antibiotics in hospitals. J Hosp Infect 2003, 53:91-96.
2. Hecker MT, Aron DC, Patel NP, Lehmann MK, Donskey C): Unnecessary use of antimicrobials in hospitalized patients. Arch Intern Med 2003, 163:972-978.

3. Usluer G, Ozgunes I, Kılıc Z, Enfez N: Evaluation of antimicrobic use in a university hospital. [Abstract]. Spanish Journal of Chemotherapy 2000, I3(Suppl I):s50.

4. John FJ Jr, Fishmen NO: Programmatic role of the infectious diseases physician in controlling antimicrobial costs in the hospital. Clin Infect Dis 1997, 24:47I-485.

5. Knox K, Lawson W, Dean B, Holmes A: Multidisciplinary antimicrobial management and the role of the infectious diseases pharmacist-a UK perspective. J Hosp Infect 2003, 53:85-90.

6. Hu S, Liu X, Peng Y: Assessment of antibiotic prescription in hospitalized patients at a Chinese university hospital. J Hosp Infect 2003, 46:16I-3.

7. Mora Y, Avila-Agüero ML, Umana MA, Jimenez AL, Paris MM, Faingezich I: Epidemiologic observations of the judicious use of antibiotics in pediatric teaching hospital. Int J Infect Dis 2002, 6:74-7.

8. Hartmann B, Junger A, Brammen D, Röhring R, Klasen J, Quinzio L, Benson M, Hempelmann G: Review of antibiotic drug use in a surgical ICU: Management with a patient data management system for additional outcome analysis in patients staying more than 24 hours. Clin Ther 2004, 26:915-24.

9. Gavrilov V, Berkovitch M, Ling G, Brenner-Zadda G, Lifshitz M, Gorodischer R: Unapproved prescriptions in two pediatric intensive care units in Israel. Curr Ther Res Clin Exp 2003, 64:734-42.

10. Bailly P, Lallemand S, Thouverez M, Talon D: Multicentre study on the appropriateness of surgical prophylaxis. J Hosp Infect 200I, 49: I35-8.

II. Kurt H: Infeksiyon hastaliklarıinda tedavi ve maliyet. Klimik Derg 2003, 16(Suppl):26I-263.

Publish with Bio Med Central and every scientist can read your work free of charge

"BioMed Central will be the most significant development for disseminating the results of biomedical research in our lifetime. " Sir Paul Nurse, Cancer Research UK

Your research papers will be:

- available free of charge to the entire biomedical community

- peer reviewed and published immediately upon acceptance

- cited in PubMed and archived on PubMed Central

- yours - you keep the copyright 